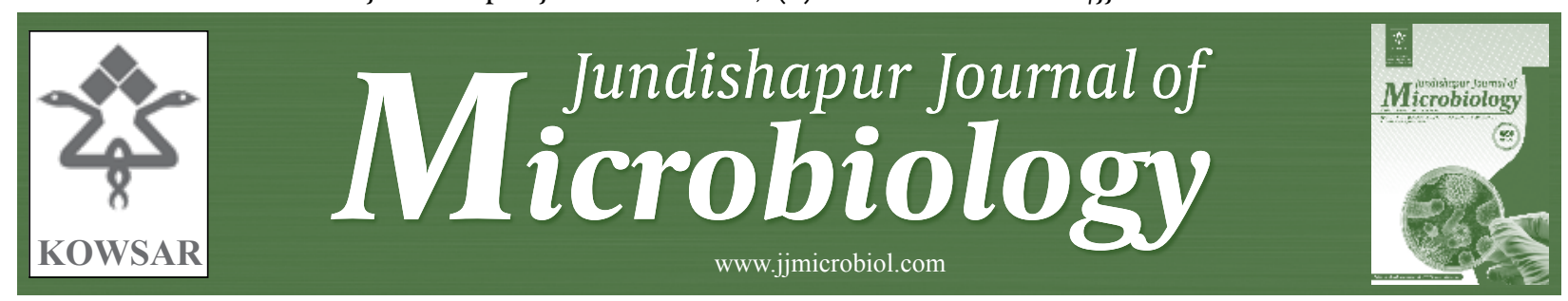

\title{
Prevalence of $\beta$-Lactamase Production and Antimicrobial Susceptibility of Multidrug Resistant Clinical Isolates of Non-Fermenting Gram Negative Bacteria From Hospitalized Patients in Kerman/Iran
}

\author{
Shahla Mansouri ${ }^{{ }^{*}}$, Mozhdeh Razavi ${ }^{1,2}$, Fatemeh Norouzi ${ }^{1}$, Sasan Gholamhoseinian Najar ${ }^{3}$ \\ ${ }^{1}$ Microbiology Department, Kerman University of Medical Sciences, Kerman, IR Iran \\ ${ }^{2}$ Faculty of Basic Sciences, Qom Branch, Islamic Azad University, Qom, IR Iran \\ ${ }^{3}$ Microbiology Department, Kerman Branch, Islamic Azad University, Kerman, IR Iran
}

\section{A R T I C L E I N F O}

Article type:

Original Article

Article history:

Received: 01 May 2011

Revised: 28 Oct 2011

Accepted: 2 Nov 2011

\section{Keywords:}

Pseudomonas aeruginosa

$\beta$-Lactamase

Multiple Drug Resistant Gene

\begin{abstract}
A B S T R A C T
Background: Non-fermenting Gram-negative bacteria are unable to ferment sugars in order to generate energy. They are ubiquitous in nature, and have a wide geographic distribution. They are also common in hospital settings, and may be isolated from humidifiers, ventilator machines, dialysis machines and other equipment, as well as from the skin of hospital personnel.

Objectives: This study focused on the isolation of multidrug resistant (MDR) non-fermenting Gram negative bacteria from clinical samples. Antimicrobial susceptibility, detection of extended spectrum $\beta$-lactamases (ESBL), and the presence of CTX-M and Metallo $\beta$-lactamase (MBL) in the isolated bacteria were evaluated.

Materials and Methods: Agar dilution method was used to test the susceptibility of the isolates to 10 antibacterial agents. All the isolates that were resistant to $\geq 3$ antibacterial agents from different classes were regarded as MDR (111 isolates) and were selected for further studies.

$\beta$-lactamase and ESBL production were detected by nitrocefin discs, combined discs (CD) and double discs plus CD (DCDT). bla $a_{\text {CIX:M }}$ and MBL were detected by PCR and EDTA synergy methods respectively.

Result: Among the MDR isolates the isolation frequency of Pseudomonas aeruoginosa, Stenotrophomonas maltophilia and Acinetoacter baumannii were 83.7\%, 9.9\% and 6.3\% respectively. Resistance to imipenem (0.9\%) and Ceftazidim (13.6\%) was low, but resistance to other $\beta$-lactams was high, and $29.7 \%$ were resistant to $\geq 6$ antibacterial agents from different classes simultaneously. $\beta$-lactamase was produced by $41.4 \%$ of the MDR isolates. Detection of ESBLs by a $\mathrm{CD}(59.4 \%)$ or DCDT test (46.8\%) was not significantly different, but with a combination of CD and DCDT a higher percentage of ESBLs in the isolates $(P \leq 0.00)$ could be detected. The $b l a_{\text {CIX-M }}$ and MBL phenotype were detected in two different strains of P. aeruoginosa.

Conclusions: The presence of a high percentage of isolates producing ESBLs which are resistant to different antibacterial agents may result in treatment failure in infected patients. Careful detection of antimicrobial resistant strains is needed in order to avoid underestimation or misidentification of ESBLs. An effective hospital infection control policy is also necessary in order to prevent further resistance to antimicrobials in the region.
\end{abstract}

Copyright $\odot 2012$ Kowsar Corp. All rights reserved.

\section{- Implication for health policy/practice/research/medical education:}

Detection of the frequency and type of extended spectrum $\beta$-lactamases (ESBL) involved in resistance to antimicrobial agents is important from a clinical and epidemiological point of view. Reporting the presence of highly resistant isolates of Pseudomonas aeruginosa producing ESBLs in this area will help physicians to select appropriate antimicrobials for empirical therapy.

* Corresponding author: Shahla Mansouri, Microbiology Department. Kerman University of Medical Sciences, P.o. Box: 7616914111, Kerman, IR Iran. Tel/Fax:+98-3413221665, E-mail: shmansouri_1000@yahoo.com

DOI: $10.5812 / j j m .3399$

Copyright $\odot 2012$ Kowsar Corp. All rights reserved. 
Please cite this paper as:

Mansouri S, Razavi M, Norouzi F, Gholamhoseinian Najar S. Prevalence of $\beta$-Lactamase Production and Antimicrobial Susceptibility of Multidrug Resistant Clinical Isolates of Non-Fermenting Gram Negative Bacteria From Hospitalized Patients in Kerman/Iran. Jundishapur J Microbiol.2012;5(2):405-10. DOI: 10.5812/jjm.3399

\section{Background}

Non-fermenting Gram-negative bacteria cannot ferment sugars in order to generate energy. These bacteria are ubiquitous in nature, with a wide geographic distribution. They are common in hospital setting, and may be found on the surface of humidifiers, ventilator machines, dialysis machines and other equipment, as well as from the skin of hospital personnel $(1,2)$. The most prevalent and important non-fermenting Gram negative bacteria in clinical laboratories are Pseudomonas aeruginosa, which is the leading cause of nosocomial infections, Acinetobacter especially A. baumannii and Stenotrophomonas maltophilia play an increasingly important role as nosocomial pathogens in compromised patients $(1,3,4)$. The prevalence and rates of resistance in these organisms to available antimicrobials are increasing $(2,5,6)$.

Of particular concern is their resistance to $\beta$-lactam antibiotics, which is usually mediated by $\beta$-lactamase production. Widespread use of extended spectrum $\beta$-lactam antibiotics has resulted in the formation of potent enzymes that are able to inactivate many of the new generation of antimicrobial agents (5). Extended spectrum $\beta$-lactamases (ESBL) are enzymes with the ability to hydrolyze the extended spectrum cephalosporins, such as cefotaxime, Ceftazidime and cefoperazone (7). ESBL production is often associated with mobile genetic elements; carrying genes that encode resistance to other antimicrobials such as aminoglycosides, sulfonamides, quinolones and trimethoprim $(2,8)$. These bacteria are usually multidrug resistant (MDR) due to the presence of low outer membrane permeability, expression of several efflux pumps and the production of extracellular enzymes to inactivate antibiotics $(2,5)$.

In Iran the majority of $P$. aeruginosa isolates are reported to be MDR, producing various types of ESBLs, such as TEM, SHV and PER (9-11). Cefotaximases are a new emerging type of $\beta$-lactamases which hydrolyze cefotaxime (CTX) more than Ceftazidime (CAZ), and in the isolates producing this type of ESBLs the minimum inhibitory concentration (MIC) for CTX is generally higher than for CAZ (8). Although these enzymes are prevalent in Enterobacteriaceae, their existence in non-fermenters is very low $(8,12-14)$. In Iran the rate of resistance to CTX in human clinical isolates of $P$. aeruginosa is very high $(9,10$, 15).

\section{Objectives}

The present study has been performed to detect drug resistance, beta lactamase and ESBL production and also to determine the possible presence of CTX-M and MBL type $\beta$-lactamases in non-fermenter gram negative iso- lates from hospitalized patients in the south-east of Iran.

\section{Materials and Methods}

MDR strains of non-fermenting Gram-negative bacteria were isolated from samples of urinary tract, blood, burns, wounds, or body fluids of patients from three hospitals in Kerman in the south-east of Iran, from December 2008 to September 2009.The isolates that were able to grow on MacConkey agar (HiMedia. India) but failed to acidify oxidative-fermentative media overlaid with mineral oil were considered to be the non-fermenters. They were identified to the species level by standard biochemical tests and microbiological methods (16). Only one isolate per patient was included in the study.

\subsection{Antimicrobial Susceptibility Testing}

Susceptibility of the bacterial isolates to 10 antimicrobial agents including: cefotaxime (CTX), ceftizoxime (ZOX), cephtazidime (CAZ), cephalexin (LEX), gentamicin (GEN), nalidixic acid (NAL), tetracycline (TET) ciprofloxacin (CIP), imipenem (IPM), and trimethoprim - sulfamethoxazole (SXT) were determined by a standard agar dilution method. The lowest concentration of antimicrobial agents which inhibited the bacterial growth was recorded as the MIC (17). The isolates that showed resistance to 3 or more antibacterial agents from different classes were regarded as MDR and were included in this study.

\subsection{Detection of $\beta$-Lactamases}

Production of $\beta$-lactamases by the isolates was tested using nitrocefin discs. ESBLs detection was performed by the combined disc (CD) method, using discs containing $30 \mu \mathrm{g}$ of CTX, CAZ, or cefpodoxime (CPD) alone or in com-

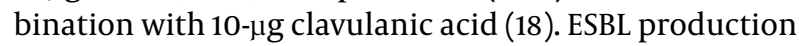
was also tested by a combination of $C D$ and double discs; DCDT $(13,18)$. In DCDT, discs of CAZ, CTX, cefepime (CPM), and CPD were placed around a disc containing amoxicillin/clavulanic acid (30/10 $\mu$ g) at a $25 \mathrm{~mm}$ center-to-center distance (Figure 1). Production of ESBL was indicated by the synergy between the CAZ, CTX and CEF and AMX/CLA disc. All discs were obtained from Mast (Mast Diagnostics, England).

\subsection{Detection of Metallo $\beta$-Lactamase (MBL) Phenotype}

Bacterial suspensions were adjusted to 0.5 McFarland, and were subsequently spread on the surface of Muller Hinton agar. MBL was detected by placing an imipenem

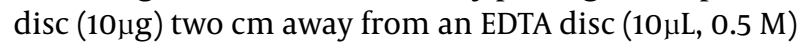
and also with an imipenem disc to which EDTA $(10 \mu \mathrm{L}, 0.5$ M) was added $(19,20)$. The plates were incubated over 


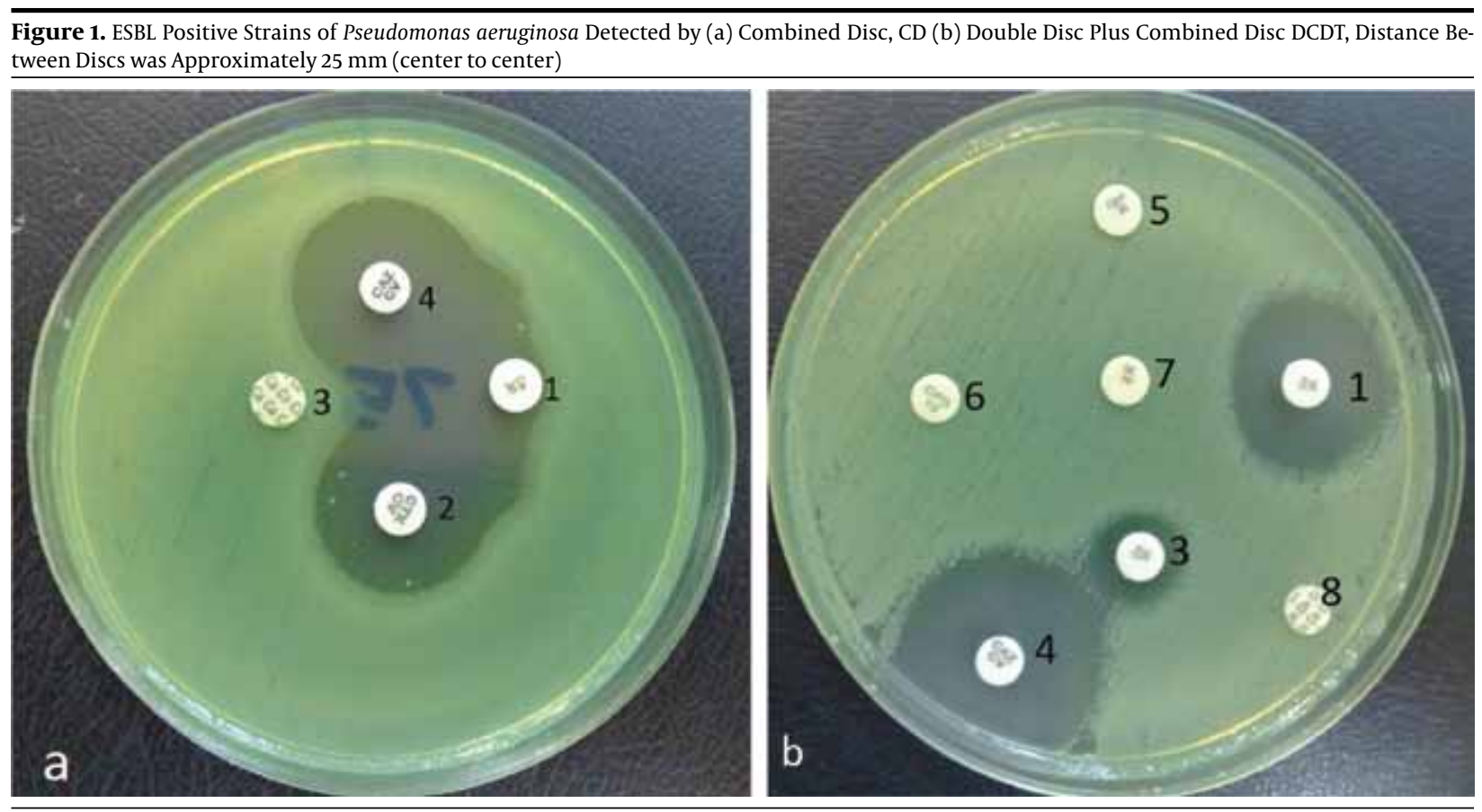

1, CTX, Cefotaxime; 2, CTX/CLA, Cefotaxime/Clavulanic Acid; 3, CAZ, Cephtazidime; 4, CAZ/CLA, Cephtazidime/Clavulanic Acid; 5, CPM, Cefepime; 6, AMX/ CLA, Amoxicillin/Clavulanic Acid; 7, CPD, Cefpodoxime; 8, FOX, Cefoxitin

night at $35^{\circ} \mathrm{C}$, enlargement of the inhibition zone $\geq 7 \mathrm{~mm}$ in the presence of the EDTA in both tests was interpreted as the EDTA synergy and a positive test $(19,20)$.

\subsection{Detection of Chromosomal AmpC Phenotype}

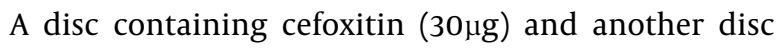
with ceftazidime/clavulanate were included in the DCDT (double disc plus combined discs) for detection of AmpC type enzymes [13]. The presence of AmpC $\beta$-lactamase in the isolate with a MBL phenotype was confirmed by CicaBeta-Test C (Mast Diagnostics, England) (21).

\subsection{PCR Assay for the Detection of CTX $\beta$ - Lactamases}

The MIC ratio for CTX to CAZ was determined for all of the ESBL positive isolates (CD and/or DCDT). A PCR assay was performed for the isolates if the MIC ratio of CTX/CAZ was $\geq 2$.Plasmid DNA was extracted by a high pure Plasmid isolation Kit (Bioneer, Accu PreP Plasmid Extraction Kit, Mannheim, Germany) and was used as a template DNA for PCR. The presence of $b l a_{\text {CTX-M }}$ was detected by PCR using MA, bla $a_{\text {CTX-M }}$ forward primer (5- CGCTTTGCGATGTGCAG-3') and MB, bla ${ }_{\text {CTX-M }}$ reverse primer ( $5^{\prime}$-ACCGCGATACGTTGGT-3 ${ }^{-}$) with an amplicon size of 550 bp (accession no X92506), that corresponds to the conserved region of CTX-M1, CTX-M 2, CTX-M 9 encoding gene $(22,23)$. The DNA amplification program consisted of an original denaturation $\left(94^{\circ} \mathrm{C}\right.$ for $\left.4.5 \mathrm{~min}\right), 30$ cycle of denaturation $\left(94^{\circ} \mathrm{C}\right.$ for $50 \mathrm{~s})$, annealing $\left(58^{\circ} \mathrm{C}\right.$ for $\left.50 \mathrm{~s}\right)$, polymerization $\left(72^{\circ} \mathrm{C}\right.$ for 50s), and an additional polymerization step $\left(72^{\circ} \mathrm{C}\right.$ for $7 \mathrm{~min}$ ). PCR products were visualized on $1.2 \%$ agarose gel and stained with ethidium bromide after electrophoresis. A 100 bp DNA ladder (Roche, Germany) was used as a size marker. Klebsiella pneumoniae ATCC 700603 was used as a positive control and the reaction mixture without primer and Escherichia coli ATCC 25922 were used as the negative control in the PCR reaction.

\subsection{Statistical Analysis}

SPSS version 11.5 (SPSS Inc. , Chicago, 111) for Windows was used to analyze the data, and a Fisher exact test was used for the categorical data. P-value of $\leq 0.05$ was considered significant (two-tailed test).

\section{Results}

In total 111 MDR non-fermenting gram negative bacteria were collected from different clinical samples. The isolated bacteria were identified as P. aeruginosa $(\mathrm{n}=93), A$. baumannii $(\mathrm{n}=7)$ and S. maltophilia $(\mathrm{n}=11)$. The majority of the isolates were from female subjects (78.5\%) compared with the male samples $(21.5 \%, P=0.001)$. Isolated bacteria from patients with urinary tract infections showed a frequency of $57.6 \%$ which was statistically more common than the isolates from burns (17.1\%), blood (11.7\%) or other miscellaneous samples (13.6\%), $P \leq 0.00$.

\subsection{Antibacterial Susceptibility and $\beta$-Lactamase Pro- duction}

Only one sample of $P$. aeruginosa isolated from the urine sample of a female patient in an internal medicine ward had low susceptibility to imipenem, showing MIC of $32 \mu \mathrm{g} / \mathrm{ml}$. This isolate was found to be an MBL producer by both methods used for the detection of MBL. The second most active agent was CAZ and $86.4 \%$ of the isolates were sensitive to this 


\begin{tabular}{|c|c|c|c|c|c|c|c|}
\hline & \multicolumn{2}{|c|}{ P. aeruginosa } & \multicolumn{2}{|c|}{ S. maltophila } & \multicolumn{2}{|c|}{ A. baumannii } & \multirow[b]{2}{*}{ Total Resistance No, \% } \\
\hline & $\begin{array}{l}\mathrm{MIC}^{\mathrm{a}} 50 / 90 \mu \mathrm{g} / \\
\mathrm{mL}\end{array}$ & $\begin{array}{l}\text { Resistance } \\
\text { No, \% }\end{array}$ & $\begin{array}{l}\text { MIC }^{\mathrm{a}} 50 / 90 \\
\mu \mathrm{g} / \mathrm{mL}\end{array}$ & $\begin{array}{l}\text { Resistance } \\
\text { No,\% }\end{array}$ & \begin{tabular}{|l}
$\mathrm{MIC}^{\mathrm{a}}$ 50/90 \\
$\mu \mathrm{g} / \mathrm{mL}$
\end{tabular} & $\begin{array}{l}\text { Resistance } \\
\text { No, \% }\end{array}$ & \\
\hline CTX $^{\mathrm{a}}$ & $16 / 64$ & $9(81.8)$ & $16 / 128$ & $67(72)$ & $256 / 256$ & $7(100)$ & $82(73.9)$ \\
\hline $\mathrm{CAZ}^{\mathrm{a}}$ & $4 / 16$ & $2(18.2)$ & $4 / 8$ & $8(8.6)$ & $128 / 256$ & $6(83.7)$ & $15(13.6)$ \\
\hline $\mathrm{ZOX}^{\mathrm{a}}$ & $16 / 128$ & $6(54.5)$ & $16 / 128$ & $59(63.4)$ & $64 / 64$ & $5(71.4)$ & $71(63.9)$ \\
\hline LEX $^{\mathrm{a}}$ & $512 / 512$ & $10(90.9)$ & $512 / 512$ & $93(100)$ & $512 / 512$ & $7(100)$ & $111(100)$ \\
\hline $\mathrm{TET}^{\mathrm{a}}$ & $4 / 16$ & $6(45.5)$ & $8 / 128$ & $56(60.2)$ & 16.128 & $7(100)$ & $67(60.4)$ \\
\hline $\mathrm{GEN}^{\mathrm{a}}$ & $32 / 64$ & $7(36.6)$ & $4 / 512$ & $34(36.6)$ & $256 / 256$ & $6(85.7)$ & $47(42.3)$ \\
\hline $\mathrm{NAL}^{\mathrm{a}}$ & $16 / 256$ & $4(36.4)$ & $32 / 512$ & $72(77.4)$ & $256 / 512$ & $6(85.7)$ & $27(24.3)$ \\
\hline $\mathrm{CIP}^{\mathrm{a}}$ & $<2 / 2$ & $4(36.4)$ & $<2 / 16$ & $17(18.3)$ & $128 / 128$ & $6(85.7)$ & $27(24.3)$ \\
\hline $\mathrm{AMX}^{\mathrm{a}}$ & $256 / 256$ & $16(90.9)$ & $128 />256$ & $93(100)$ & $256 / 256$ & $7(100)$ & $109(98.2)$ \\
\hline SXT $^{\mathrm{a}}$ & $4 / 32$ & $7(63.6)$ & $4 / 128$ & $49(52.7)$ & $2 / 32$ & $3(42.9)$ & $59(53.2)$ \\
\hline
\end{tabular}

a Abbreviations: CTX, Cefitizoxime; CAZ, Cephtazidime; ZOX, Cefotaxime; LEX, Cephalexin; TET, Tetracycline; GEN, Gentamicin; NAL, Nalidixic Acid; CIP, Ciprofloxacin; AMX, Amoxicillin; SXT, Trimethoprim-Sulfamethoxazole; MIC: Minimal inhibitory concentration

agent. Resistance to other antibacterial agents ranged from $24.3 \%$ for CIP to $100 \%$ for LEX(Table 1). The $\mathrm{MIC}_{50}$ and $\mathrm{MIC}_{90}$ of $A$. baumannii for all the antibacterial agents tested (except IPM) were in the resistance category (Table 1), and the mean MIC for all antibacterial agents except SXT, AMX and LEX was significantly higher than either $P$. aeruginosa or S. maltophilia $(P \leq$ 0.000 , results not shown). In these isolates simultaneous resistance to $3,4,5$ and $\geq 6$ antibacterial agents were $17.1 \%, 32.4 \%$, $20.7 \%$ and $29.7 \%$ respectively.

Resistance to all antibacterial agents was found in $5.4 \%$ of the isolates. The most common pattern of resistance was NAL, TET and $\beta$-lactams. The most frequent pattern of MDR resistance in P. aeruginosa was resistance to a $\beta$-lactams simultaneously with NAL and TET (26.9\%) or with NAL or CIP, TET, SXT and GEN (21.5\%). Nearly half of the isolated A. baumannii showed resistance to ß-lactams plus GEN, TET, CIP (42.9\%) or $\beta$-lactam with GEN, TET, CIP (42.9\%). S. maltophilia isolates showed no special pattern of resistance. The rate of $\beta$-lactamase production detected by the nitrocefin discs was significantly higher in $A$. baumannii compared to P. aeruginosa or S. maltophilia isolates $(P \leq 0.001$, Figure 2$)$. ESBL production was higher in A. baumannii compared to the other bacterial species tested but the difference was not significant. A higher percentage of isolates

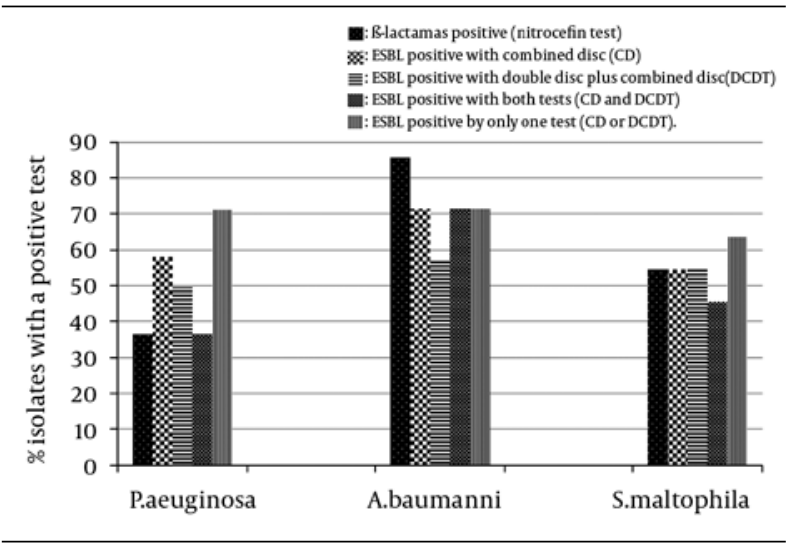

Figure 2. Percent $\beta$-Lactamase and ESBL Production in P. aeruginosa, $A$. baumanni and S. malthophila. was detected as ESBL producers when the positive results in the $\mathrm{CD}$ and DCDT tests were added together $(P \leq 0.007)$.

\subsection{AmpC Production by the Isolates}

All of the isolates were resistant to cefoxitin indicating the possibility of an inducible AmpC type $\beta$-lactamase in these isolates.

\subsection{Frequency of Isolation of bla $a_{C T X-M}$ Type $\beta$-Lactamases by PCR}

The PCR method for the detection of the $b l a_{\text {CTX-M }}$ gene was performed on those ESBL positive isolates with an MIC ratio of CTX/CAZ greater or equal to $2(n=37)$. The

Figure 3. PCR Amplification of CTX-M Gene in a Strain of Pseudomonas aeruginosa

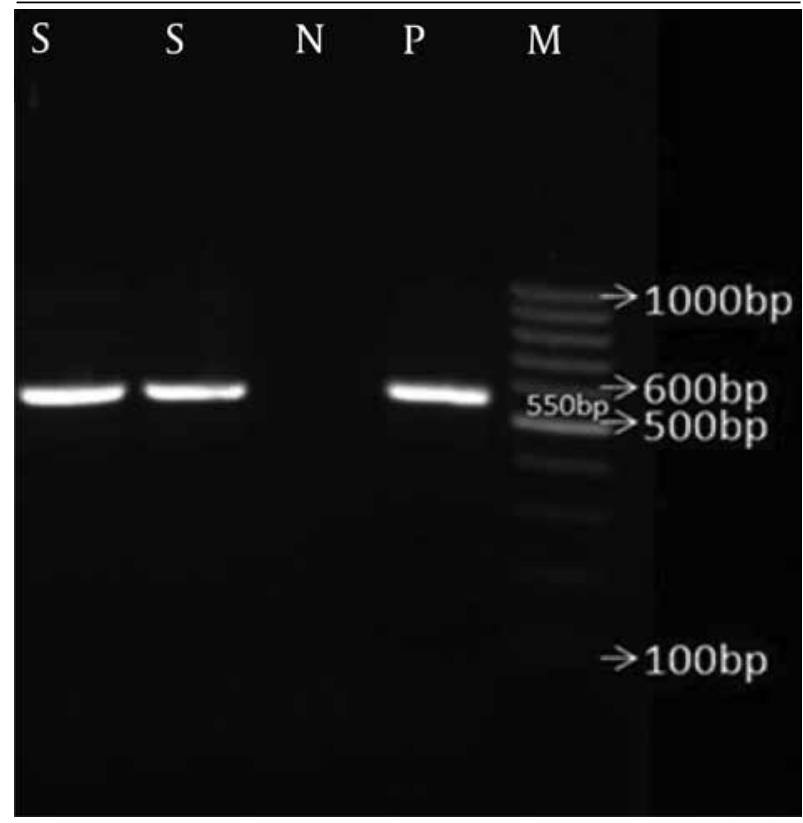

Lane M,100bp Ladder, P-Positive Control(Klebsiella pneumoniae ATCC 700603), N-Negative Control (E. coli ATCC 25922), and S; Sample Run in Duplicate. 
results showed one P. aeruginosa strain to be CTX-M positive (Figure 3).

\section{Discussion}

The incidence of multiple drug resistant clinical isolates of enteric and non-fermenting Gram-negative rods from clinical samples in Iran is increasing (24). Multiple drug resistant bacteria are a major cause of life threatening infections for patients dealing with them $(1,6)$. In the present study resistance in non-fermenting Gram-negative rods to $\beta$-lactams was very high and approximately $98 \%$ of the isolates were resistant to cefoxitin, cefepime, cephalexin and amoxicillin. Resistance to cephalexin and amoxicillin is very common in non-fermenters and they do not effect Pseudomonas (25). Cefepime is among the fourth generation of cephalosporins and is widely used to treat severe infections caused by $P$. aeruginosa, in addition cefoxitin which is grouped in the second generation of cephalosporins also has a good response against Pseudomonas (26). Resistance to these agents could be due to the low outer membrane permeability of non-fermenters. Production of AmP C type $\beta$-lactamases is the other resistance mechanism, however these kinds of enzymes usually have a minimal effect on the activity of cefepime $(25,27)$. Clinically isolated strains of Pseudomonas which are resistant to cefepime but sensitive to CAZ have also been reported by Aubert et al.(28). The incidence of cefepime resistant, ceftazidim sensitive isolates is due to the production of class D- $\beta$-lactamases, or over expression of the efflux system (29). Cefepime resistance, ceftazidime sensitive isolates, as well as GEN and CIP resistant phenotypes found in this study could be due to the stable over expression of the efflux system MexXY in $P$. aeruginosa $(25,29)$. Since the bacterial isolates in this study were mostly sensitive to CAZ but resistant to CPM, studying this type of resistance may identify the mechanism of resistance to $\beta$-lactams and many other antimicrobial agents in these bacteria.

Carbapenems are still active against many strains of non-fermenters, although resistance to these agents is increasing (2). We detected only one IPM resistant isolate in our study. This isolate was resistant to all antibacterial agents tested and was positive for MBL phenotype by both applied methods. Isolation of the IPM resistant strain in this study has significant clinical benefits both in the treatment of infections caused by these bacteria and in restricting the use of these types of antibacterial agents in order to avoid the emergence of further resistant isolates.

ESBL detection by the CD method detected a higher percentage of ESBL phenotypes than the DCDT test, but the difference was not significant. However the combination of the two tests was found to be superior and led to a higher rate of ESBL detection compared to using each test alone $(P \leq 0.007)$. Among the various ESBLs types detected so far, the CTX-M type is reported to be the most prevalent ESBL in Enterobacteriaceae from various geographic areas including Iran $(26,30,31)$. These enzymes are not frequently seen in non-fermenters, and for the first time CTX-M producing $P$. aeruginosa and S. maltophilia were reported from the Netherlands in 2006 [13]. In Iran CXT-M positive $P$. aeruginosa has been reported in Kurdistan (32). The CTX-M positive isolate in this study showed no inhibition zone around the disc containing CAZ, CTX, or CPD with or without clavulanic acid. The presence of AmpC type $\beta$-lactamase by a CICA Beta test $C$ strip was confirmed in this isolate, which may be the reason for its resistance to a combination of clavulanic acid and cephalosporins. Since only one primer was used in this study and the isolates were selected based on the ratio of CAZ/CTX, the actual prevalence of CTX-M may be higher than our findings. Sequencing of positive CTX-M gene found in this study is required to determine the type of involved enzyme. More investigations are also needed to determine the mechanism of high levels of resistance to cefotaxime and the possible presence of other types of CTX-M genes that may be involved in the incidence of this resistance.

In conclusion we found a high percentage of ESBL production among MDR isolates of non-fermenters in this study. ESBL production appeared to be a significant mechanism for the incidence of resistance in these isolates. The selection of an antimicrobial agent in the treatment of infections caused by non-fermenters should be based on the assumption that AmpC $\beta$-lactamase production can be induced by certain cephalosporins. Careful detection of ESBL production in the MDR isolates should be performed preferably by two methods in order to avoid misidentification of the ESBLs. Careful choice of antimicrobial chemotherapy based on the surveillance programs is necessary to avoid treatment failures.

\section{Acknowledgments}

We thank the Research Council of Kerman University of Medical Sciences and Azad University of Qom for the financial support.

\section{Financial Disclosure}

None declared.

\section{Funding/Support}

Kerman University of Medical Sciences and Islamic Azad University of Qom.

\section{References}

1. Enoch DA, Birkett CI, Ludlam HA. Non-fermentative Gram-negative bacteria. Int J Antimicrob Agents. 2007;29 (Suppl 3):S33-41.

2. McGowan JE, Jr. Resistance in nonfermenting gram-negative bacteria: multidrug resistance to the maximum. Am J Med P. 2006;119 (Suppl 1):S29-36; discussion S62-70.

3. Bergogne-Berezin E. The Increasing Role of Acinetobacter Species As Nosocomial Pathogens. Curr Infect Dis Rep. 2001;3 (5):440-4.

4. Senol E. Stenotrophomonas maltophilia: the significance and 
role as a nosocomial pathogen. J Hos P Infect. 2004;57 (1):1-7.

5. Livermore DM, Woodford N. The beta-lactamase threat in Enterobacteriaceae, Pseudomonas and Acinetobacter. Trends Microbiol. 2006;14 (9):413-20.

6. Mesaros N, Nordmann P, Plesiat P, Roussel-Delvallez M, Van Eldere J, Glupczynski Y, et al. Pseudomonas aeruginosa: resistance and therapeutic options at the turn of the new millennium. Clin Microbiol Infect. 2007;13 (6):560-78.

7. Paterson DL, Bonomo RA. Extended-spectrum beta-lactamases: a clinical update. Clin Microbiol Rev. 2005;18 (4):657-86.

8. Walther-Rasmussen J, Hoiby N. Cefotaximases (CTX-M-ases), an expanding family of extended-spectrum beta-lactamases. Can J Microbiol. 2004;50 (3):137-65.

9. Mirsalehian A, Feizabadi M, Nakhjavani FA, Jabalameli F, Goli H, Kalantari N. Detection of VEB-1, OXA-10 and PER-1 genotypes in extended-spectrum beta-lactamase-producing Pseudomonas aeruginosa strains isolated from burn patients. Burns. 2010;36 (1):70-4.

10. Shakibaei MR, Shah CF, Hashemi A, SaeidAdeli NA. Detection of TEM, SHV and PER type extended-spectrum $\beta$-lactamasegenes among clinical strains of Pseudomonas aeruginosa isolated from burnt patients at Shafa-hospital, Kerman, Iran. Iran J Basic Med Sci. 2008;11 (2):104-11.

11. Shahcheraghi F, Nikbin VS, Feizabadi MM. Prevalence of ESBLs genes among multidrug-resistant isolates of Pseudomonas aeruginosa isolated from patients in Tehran. Microb Drug Resist. 2009;15 (1):37-9.

12. al Naiemi N, Bart A, de Jong MD, Vandenbroucke-Grauls CM, Rietra PJ, Debets-OssenkopP YJ, et al. Widely distributed and predominant CTX-M extended-spectrum beta-lactamases in Amsterdam, The Netherlands. J Clin Microbiol. 2006;44 (8):3012-4.

13. al Naiemi N, Duim B, Bart A. A CTX-M extended-spectrum betalactamase in Pseudomonas aeruginosa and Stenotrophomonas maltophilia. J Med Microbiol. 2006;55 (Pt 11):1607-8.

14. Pellegrino FL, Teixeira LM, Carvalho Md Mda G, Aranha Nouer S, Pinto De Oliveira M, Mello Sampaio JL, et al. Occurrence of a multidrug-resistant Pseudomonas aeruginosa clone in different hospitals in Rio de Janeiro, Brazil. J Clin Microbiol. 2002;40 (7):2420-4.

15. Shahcheraghi F, Feizabadi MM, Yamin V, Abiri R, Abedian Z. Serovar determination, drug resistance patterns and plasmid profiles of Pseudomonas aeruginosa isolated from burn patients at two hospitals of Tehran (IRAN). Burns. 2003;29 (6):547-51.

16. Mac Faddin JF. Biochemical tests for identification of medical bacteria. Williams \& Wilkins Co. ; 1980.

17. Wayne PA. Methods for dilution antimicrobial susceptibility tests for bacteria that grow aerobically: approved standard. Clinical and Laboratory Standard Institute,Wayne,PA. 2006;29 (2):M07-A8.

18. Quiroga M, Teresa Lezcano M, Gerula P, Valle M, Vergara M, Villalba $\mathrm{V}$. Comparison of screening methods for detection of extendedspectrum beta-lactamase producing strains isolated in Posadas, Misiones, Argentina. Int J Antimicrob Agents. 2002;20 (4):307-8.
19. Chacko B, Varaiya A, Dedhia B. Imipenem resistant metallo beta lactamase producing Pseudomonas aeruginosa. Indian J Med Microbiol. 2008;26 (4):398.

20. Jesudason MV, Kandathil AJ, Balaji V. Comparison of two methods to detect carbapenemase \& metallo-beta- lactamase production in clinical isolates. Indian J Med Res. 2005;121 (6):780-3.

21. Livermore DM, Warner M, Mushtaq S. Evaluation of the chromogenic Cica-beta-Test for detecting extended-spectrum, AmpC and metallo-beta-lactamases. J Antimicrob Chemother. 2007;60 (6):1375-9.

22. Bonnet R, Dutour C, Sampaio JL, Chanal C, Sirot D, Labia R, et al. Novel cefotaximase (CTX-M-16) with increased catalytic efficiency due to substitution Asp-240-- > Gly. Antimicrob Agents Chemother. 2001;45 (8):2269-75.

23. Brasme L, Nordmann P, Fidel F, Lartigue MF, Bajolet O, Poirel L, et al. Incidence of class A extended-spectrum beta-lactamases in Champagne-Ardenne (France): a 1 year prospective study. J Antimicrob Chemother. 2007;60 (5):956-64.

24. Irajian $G$, Jazayeri Moghadas A. Frequency of extended-spectrum beta lactamase positive and multidrug resistance pattern in Gram-negative urinary isolates, Semnan, Iran. Jundishapur J Microbiol. 2010;3 (3):107-13.

25. Marcus N, Ashkenazi S, Samra Z, Cohen A, Livni G. Communityacquired Pseudomonas aeruginosa urinary tract infections in children hospitalized in a tertiary center: relative frequency, risk factors, antimicrobial resistance and treatment. Infection. 2008;36 (5):421-6.

26. Hocquet D, Nordmann P, El Garch F, Cabanne L, Plesiat P. Involvement of the MexXY-OprM efflux system in emergence of cefepime resistance in clinical strains of Pseudomonas aeruginosa. Antimicrob Agents Chemother. 2006;50 (4):1347-51

27. Tomas M, Doumith M, Warner M, Turton JF, Beceiro A, Bou G, et al. Efflux pumps, OprD porin, AmpC beta-lactamase, and multiresistance in Pseudomonas aeruginosa isolates from cystic fibrosis patients. Antimicrob Agents Chemother. 2010;54 (5):2219-24.

28. Aubert D, Poirel L, Chevalier J, Leotard S, Pages JM, Nordmann P. Oxacillinase-mediated resistance to cefepime and susceptibility to ceftazidime in Pseudomonas aeruginosa. Antimicrob Agents Chemother. 2001;45(6):1615-20.

29. Hocquet D, Muller A, Blanc K, Plesiat P, Talon D, Monnet DL, et al. RelationshiP between antibiotic use and incidence of MexXYOprM overproducers among clinical isolates of Pseudomonas aeruginosa. Antimicrob Agents Chemother. 2008;52 (3):1173-5.

30. Canton R, Coque TM. The CTX-M beta-lactamase pandemic. Curr Opin Microbiol. 2006;9 (5):466-75.

31. Mirzaee M, Pourmand MR, Chitsaz M, Mansouri S. Antibiotic Resistance to Third Generation Cephalosporins Due to CTX-M-Type Extended-Spectrum $\beta$-Lactamases in Clinical Isolates of Escherichia coli. Iranian J Publ Health. 2009;38 (1):10-7.

32. Ramazanzadeh R, Chitsaz M, Bahmani N. Prevalence and antimicrobial susceptibility of extended-spectrum beta-lactamaseproducing bacteria in intensive care units of Sanandaj general hospitals (Kurdistan, Iran). Chemotherapy. 2009;55 (4):287-92. 